\title{
Stress-Corrosion Cracking Property of Aluminum-Magnesium Alloy Processed by Equal-Channel Angular Pressing
}

\author{
Hiroaki Nakano, ${ }^{1}$ Satoshi Oue, ${ }^{1}$ Seiji Taguchi, ${ }^{2,3}$ Shigeo Kobayashi, ${ }^{4}$ and Zenji Horita ${ }^{1}$ \\ ${ }^{1}$ Department of Materials Science \& Engineering, Kyushu University, 744 Motooka, Nishi-ku, Fukuoka 819-0395, Japan \\ ${ }^{2}$ Department of Materials Process Engineering, Kyushu University, 744 Motooka, Nishi-ku, Fukuoka 819-0395, Japan \\ ${ }^{3}$ JFE Steel Corporation, Japan \\ ${ }^{4}$ Department of Applied Chemistry and Biochemistry, Kyushu Sangyo University, 2-3-1 Matsukadai, Higashi-ku, \\ Fukuoka 813-8503, Japan
}

Correspondence should be addressed to Hiroaki Nakano, nakano@zaiko.kyushu-u.ac.jp

Received 26 December 2011; Revised 19 January 2012; Accepted 19 January 2012

Academic Editor: Rokuro Nishimura

Copyright (C) 2012 Hiroaki Nakano et al. This is an open access article distributed under the Creative Commons Attribution License, which permits unrestricted use, distribution, and reproduction in any medium, provided the original work is properly cited.

\begin{abstract}
Stress-corrosion cracking property of an aluminum-magnesium alloy processed by equal-channel angular pressing (ECAP) was investigated by a slow strain-rate tensile technique in a $3 \% \mathrm{NaCl}$ solution of $\mathrm{pH} 4.2$ at $303 \mathrm{~K}$. The maximum stress and elongation of the $\mathrm{Al}-\mathrm{Mg}$ alloy were lower in the $\mathrm{NaCl}$ solution than in air. The stress-corrosion cracking property was evaluated by the decrease ratio of maximum stress and elongation of the Al-Mg alloy with $\mathrm{NaCl}$ solution, $I\left(\delta_{\max }\right)$ and $I(\delta)$, respectively. $I\left(\delta_{\max }\right)$ and $I(\delta)$ were lower with ECAP than without it, showing that the susceptibility of stress-corrosion cracking decreased with ECAP. The polarization curve and time dependence of the anodic current density at constant potential of the $\mathrm{Al}-\mathrm{Mg}$ alloy in the $\mathrm{NaCl}$ solution revealed that the anodic current density was lower with ECAP than without it, or the corrosion resistance of the Al-Mg alloy was improved by ECAP. The decrease in stress-corrosion crack susceptibility of the Al-Mg alloy with ECAP is attributed to an improvement in corrosion resistance afforded by ECAP.
\end{abstract}

\section{Introduction}

Although aluminum is an inherently active metal, it shows excellent corrosion resistance over a neutral range of $\mathrm{pH} 4$ 8 owing to its superficial oxide film. However, in solutions containing $\mathrm{Cl}^{-}$, pitting corrosion occurs locally where the oxide film is attacked by $\mathrm{Cl}^{-}[1,2]$. When additional stress is applied, stress-corrosion cracking also occurs along the crystal grain boundary, resulting in serious damage [35]. On the other hand, reducing the grain size of metallic materials to the submicrometer or even the nanometer range by equal-channel angular pressing (ECAP), high-pressure torsion (HPT), or a severe torsion-straining process (STSP) is being studied increasingly with the aim of improving mechanical properties such as strength and ductility [611]. The effect of severe plastic deformation on the pitting corrosion resistance of $\mathrm{Al}$ alloys has been reported [12-15]; however, reports on the effect of stress-corrosion cracking are rare.
In this study, the stress-corrosion cracking property of an alloy of $\mathrm{Al}-3 \% \mathrm{Mg}$ (by mass) processed by ECAP was investigated. Stress-corrosion cracking property was evaluated by a slow strain-rate tensile technique in a $3 \% \mathrm{NaCl}$ solution. Since the stress-corrosion cracking property of the Al-Mg alloy was expected to depend on corrosion resistance, the effect of ECAP on the corrosion resistance of the Al$\mathrm{Mg}$ alloy was investigated by polarization curves and the anodic current density at constant potential in the $\mathrm{NaCl}$ solution. The fracture area after the slow strain-rate tensile test was analyzed by scanning electron microscopy (SEM) at ultralow accelerating voltage and electron backscatter diffraction (EBSD).

\section{Experimental}

An Al-Mg alloy (mass \%, $<0.001 \% \mathrm{Cu}, 0.004 \% \mathrm{Si}, 0.001 \%$ $\mathrm{Fe},<0.001 \% \mathrm{Mn}, 3.0 \% \mathrm{Mg},<0.001 \% \mathrm{Zn},<0.001 \% \mathrm{Cr}$, and remainder $\mathrm{Al}$ ) was used as the specimen. ECAP was 
performed after annealing at $773 \mathrm{~K}$ for $1 \mathrm{~h}$ followed by air cooling. Figure 1 shows a schematic diagram of the ECAP process. ECAP was conducted for eight passes at room temperature using a die with a channel angle of $90^{\circ}$, which creates an equivalent strain of $\sim 1$ during one passage through the die. The sample was rotated $90^{\circ}$ about the longitudinal axis in the same manner between consecutive passes, the generally designated processing route $\mathrm{Bc}$ [9]. In route $\mathrm{Bc}, \mathrm{ECAP}$ changes the strain path by rotating the work piece $90^{\circ}$ clockwise between two adjacent passes. The pressings were performed at a rate of $\sim 19 \mathrm{~mm} \mathrm{~s}^{-1}$ using $\mathrm{MoS}_{2}$ as a lubricant. The initial grain size of the Al-Mg alloy prior to ECAP was $800 \mu \mathrm{m}$. The average grain size after the ECAP process was confirmed to be $0.5 \mu \mathrm{m}$ by SEM observation.

Figure 2 is a schematic diagram of a specimen prepared for the slow strain-rate tensile test. The specimens were cut from a columnar ingot by electrical discharge machining. The tensile test area was $5 \mathrm{~mm}$ long, $4 \mathrm{~mm}$ wide, and $2 \mathrm{~mm}$ thick. The notch was $500 \mu \mathrm{m}$ deep with a $0.3 \mathrm{~mm}$ radius of curvature, and a $60^{\circ}$ angle was introduced into two spots of the tensile test area, as shown in Figure 2(b). The strain rate for the slow strain-rate tensile technique was $6.67 \times 10^{-5} / \mathrm{s}$ and $1.67 \times 10^{-6} / \mathrm{s}$ in air and the corrosive solution, respectively. The entire area outside the area of the tensile test was sealed by painting to prevent the specimen from contacting the $\mathrm{NaCl}$ solution. Alkaline cleaning in $10 \% \mathrm{NaOH}$ solution, neutralization in $10 \% \mathrm{HNO}_{3}$, each for $30 \mathrm{sec}$, rinsing in pure water, and drying were performed in that order. The corrosive solution was composed of a $3 \%$ $\mathrm{NaCl}$ solution at $303 \mathrm{~K}$. The $\mathrm{pH}$ was adjusted to 4.2 with $\mathrm{HCl}$ solution.

Specimens $1.0 \mathrm{~cm}$ in diameter were prepared for corrosion testing as described below. Their corrosion resistance was investigated over an area $6 \mathrm{~mm}$ in diameter, and the remaining area was sealed with waterproof tape to prevent any corrosion from the edge. After the Al-Mg alloy was carefully polished with no. 1500 emery paper and immersed in a solution containing $0.1 \mathrm{~mol} / \mathrm{L}$ of $\mathrm{Na}_{2} \mathrm{SO}_{4}$ and $8.46 \mathrm{mmol} / \mathrm{L}$ of $\mathrm{NaCl}\left(300 \mathrm{ppm} \mathrm{Cl}^{-}\right)$at $303 \mathrm{~K}$ for $30 \mathrm{~min}$ in an air atmosphere, the polarization curves were measured by polarizing from $-0.7 \mathrm{~V}$ versus NHE in the anodic potential direction by the potential sweep method at $0.5 \mathrm{mV} \mathrm{s}^{-1}$. The time dependence of anodic current density was measured at a constant potential of $-0.2 \mathrm{~V}$ after immersion for $30 \mathrm{~min}$ in the previous solution. The electrode potentials were measured during potential sweep using a saturated $\mathrm{Ag} / \mathrm{AgCl}$ reference electrode ( $0.199 \mathrm{~V}$ versus NHE, $298 \mathrm{~K})$. In the presentation of polarization curves, the potentials were plotted with reference to NHE.

The fracture surface after the slow strain-rate tensile test was observed by SEM and confocal laser scanning microscopy. The specimen was cut perpendicularly to a fracture surface and embedded in a conductive resin to investigate the internal texture after the tensile test. The specimen was analyzed by an ultralow accelerating voltage SEM (Carl Zeiss Ultra 55) and EBSD to generate electron backscatter patterns (EBSPs) after mirror polishing and Ar sputtering.

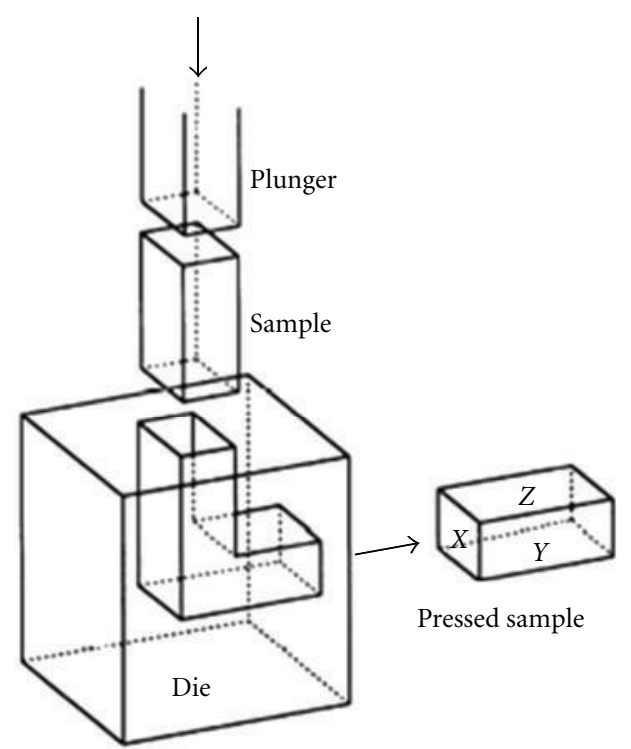

FIGURE 1: Schematic diagram of ECAP.

\section{Results and Discussion}

3.1. Effect of ECAP on Stress-Corrosion Cracking of Al-Mg Alloy. Figure 3 shows confocal laser scanning microscope images of the fracture surface of Al-Mg alloy after a slow strain-rate tensile test in air and $\mathrm{NaCl}$ solution. The $\mathrm{Al}-\mathrm{Mg}$ alloy without ECAP shows evident necking (Figures 3(a) and $3(\mathrm{~b})$ ), while with ECAP hardly any necking is visible (Figures 3(c), 3(d)). In the Al-Mg alloy without ECAP, the cracks were observed to advance from the notch to the center in $\mathrm{NaCl}$ solution (Figure 3(b)).

Figure 4 shows SEM images of the fracture surface of the Al-Mg alloy after a slow strain-rate tensile test in air and $\mathrm{NaCl}$ solution. Pitting corrosion was observed tensioned in $\mathrm{NaCl}$ solution (Figure 4(b)). This pitting corrosion seems to promote the cracking. Dimples were observed with ECAP tensioned in air and $\mathrm{NaCl}$ solution (Figures 4(c) and 4(d)), showing ductile fracture. Even in the $\mathrm{NaCl}$ solution, clear pitting corrosion was barely visible in the $\mathrm{Al}-\mathrm{Mg}$ alloy with ECAP (Figure 4(c)). As mentioned above, the fracture surface of the Al-Mg alloys with and without ECAP showed the ductile one even in $\mathrm{NaCl}$ solution, not clear the stresscorrosion cracking. However, since the pitting corrosion was observed and seems to promote the cracking after a slow strain-rate tensile test in $\mathrm{NaCl}$ solution, the cracking was assumed to be caused by both the stress and corrosion. Therefore, the cracking after a slow strain-rate tensile test in $\mathrm{NaCl}$ solution was expressed by the stress-corrosion cracking in this study.

Figure 5 shows the stress-strain diagram of the Al-Mg alloy obtained by a slow strain-rate tensile test in air and a $3 \% \mathrm{NaCl}$ solution. As seen from the stress-strain diagram in air (grey and blue), the maximum stress increased from approximately 150 to $370 \mathrm{MPa}$ by ECAP, while the total elongation decreased from approximately 0.6 to 0.15 . This trend agrees with the properties of ultrafine-grained $\mathrm{Al}$ alloy 


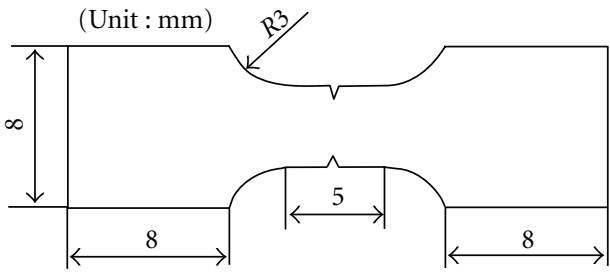

(a)
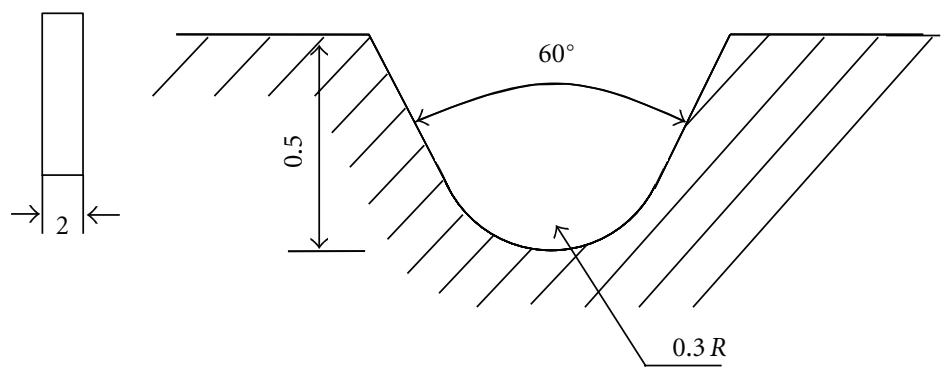

(b)

Figure 2: Tensile specimen (a) and magnification of notch (b) for slow strain-rate tensile test.

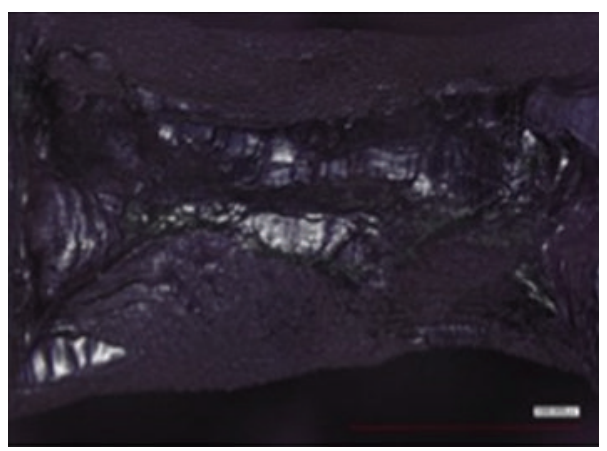

(a) Without ECAP, air

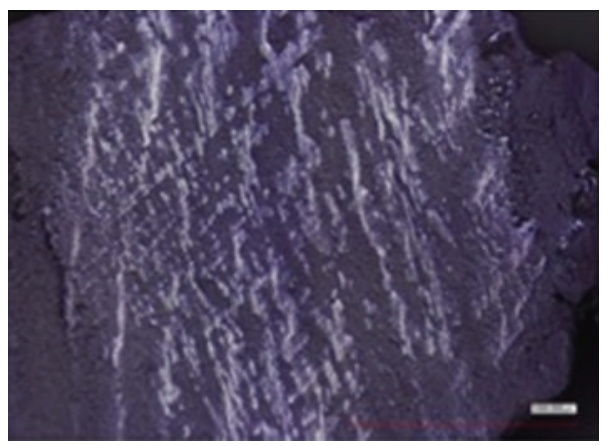

(c) With ECAP, air

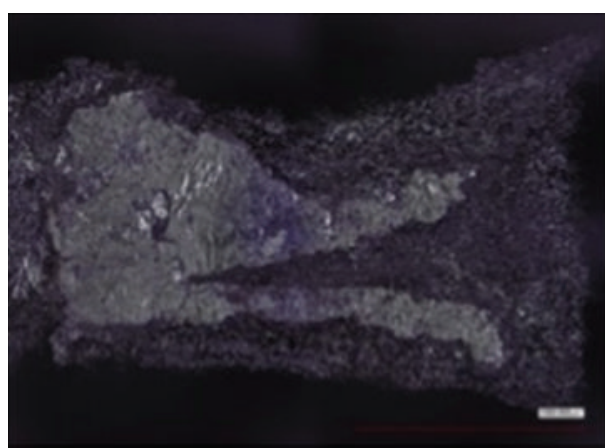

(b) Without ECAP, $\mathrm{NaCl}$ sol

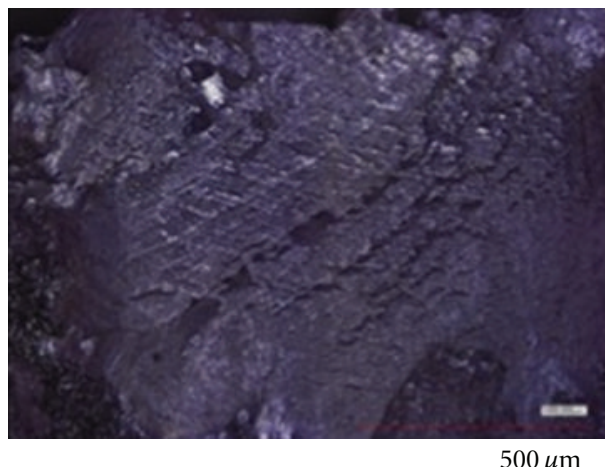

(d) With ECAP, $\mathrm{NaCl}$ sol

FIGURE 3: Confocal laser scanning microscope images of fracture surface of Al-Mg alloy with and without ECAP after slow strain-rate tensile test.

processed by ECAP [9-11]. The strength and elongation of the $\mathrm{Al}-\mathrm{Mg}$ alloy without ECAP were significantly lower in the $\mathrm{NaCl}$ solution than in air (blue and red). The reason that specimens without the ECAP process showed different tensile stress and fracture strain on depending on the tensile circumstance seems to be due to stress-corrosion cracking. In both air and $\mathrm{NaCl}$ solution, the strength of the $\mathrm{Al}-\mathrm{Mg}$ alloy was higher with ECAP (grey and pink) than without it (blue and red), while the elongation was lower with ECAP than without it. In the Al-Mg alloy with ECAP, as seen from the comparison of stress-strain curves in air (grey) and the $\mathrm{NaCl}$ solution (pink), the strength was lower in the $\mathrm{NaCl}$ solution than in air, while the elongation in the $\mathrm{NaCl}$ solution was almost identical to that in air

$$
\begin{gathered}
I\left(\sigma_{\mathrm{max}}\right)=\frac{\sigma_{\mathrm{air}}-\sigma_{\mathrm{sol}}}{\sigma_{\text {air }}}, \\
I(\delta)=\frac{\delta_{\mathrm{air}}-\delta_{\mathrm{sol}}}{\delta_{\text {air }}} .
\end{gathered}
$$

Stress-corrosion crack susceptibility was evaluated by $I\left(\sigma_{\max }\right)$ and $I(\delta)$, which express the decrease ratio of maximum 


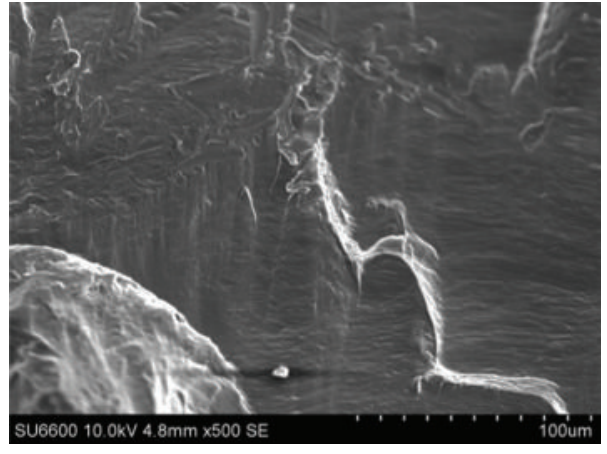

(a) Without ECAP, air

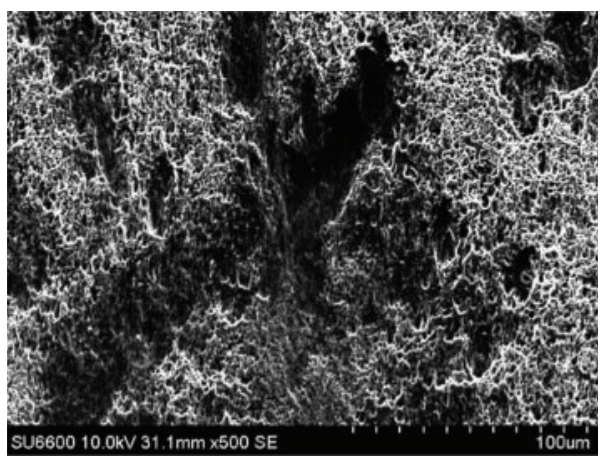

(c) With ECAP, air

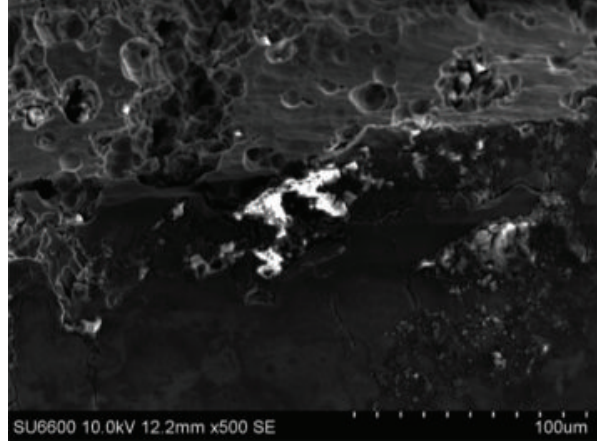

(b) Without ECAP, $\mathrm{NaCl}$ sol

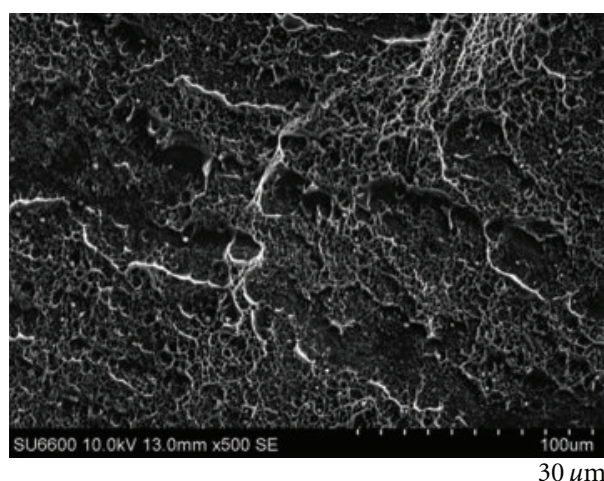

(d) With ECAP, $\mathrm{NaCl}$ sol

FIGURE 4: SEM images of fracture surface of Al-Mg alloy with and without ECAP after slow strain-rate tensile test.

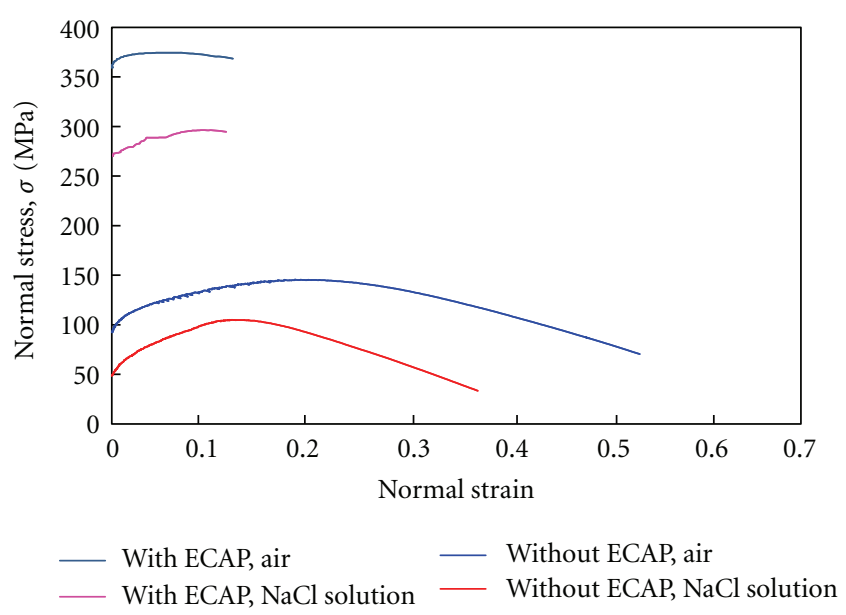

Figure 5: Stress-strain curves of Al-Mg alloy obtained by slow strain-rate tensile test.

stress and total elongation in the $\mathrm{NaCl}$ solution to those in air (1), where $\sigma_{\text {air }}$ and $\sigma_{\text {sol }}$ are the maximum stress in air and $\mathrm{NaCl}$ solution, respectively, and $\delta_{\text {air }}$ and $\delta_{\text {sol }}$ are the total elongation in air and $\mathrm{NaCl}$ solution, respectively $[3,4]$. $I(\delta)$ seems to be more suitable for stress-corrosion crack susceptibility than $I\left(\sigma_{\max }\right)$ [4]. Table 1 shows the $I\left(\sigma_{\max }\right)$ and $I(\delta)$ calculated by the maximum stress and total elongation obtained from the stress-strain curves in Figure 5. $I\left(\sigma_{\max }\right)$

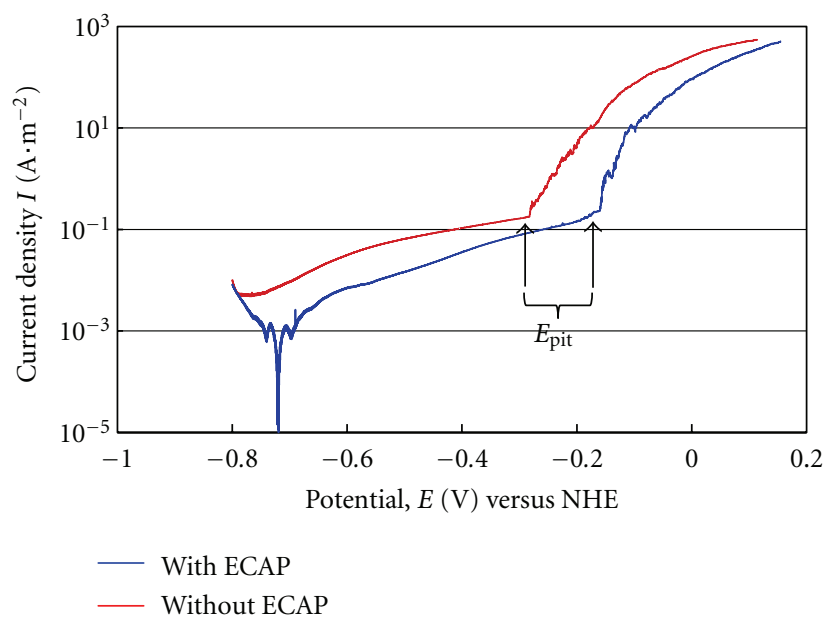

Figure 6: Polarization curves of Al-Mg alloy with and without ECAP in a solution containing $0.1 \mathrm{~mol} \cdot \mathrm{L}^{-1}$ of $\mathrm{Na}_{2} \mathrm{SO}_{4}$ and $300 \mathrm{ppm}$ $\mathrm{Cl}^{-}$.

and $I(\delta)$ were decreased by ECAP. $I(\delta)$ was significantly lower with ECAP than without it. $I\left(\sigma_{\max }\right)$ and $I(\delta)$ show that the stress-corrosion crack susceptibility of the Al-Mg alloy is smaller with ECAP than without it.

The corrosion resistance of the Al-Mg alloy was investigated to elucidate why $I\left(\sigma_{\max }\right)$ and $I(\delta)$ were decreased by ECAP. Figure 6 shows the effect of ECAP on the polarization 
TABLE 1: Susceptibility of stress-corrosion cracking of Al-Mg alloy with and without ECAP.

\begin{tabular}{lcccc}
\hline Alloy & Environment & $\sigma_{\max }(\mathrm{Mpa})$ & $\delta$ & $I\left(\sigma_{\max }\right)$ \\
\hline \multirow{2}{*}{ Without ECAP } & Air & 145 & 0.613 & 0.28 \\
& $\mathrm{NaCl}$ solution & 105 & 0.425 & 0.31 \\
\multirow{2}{*}{ With ECAP } & Air & 374 & 0.141 & 0.21 \\
& $\mathrm{NaCl}$ solution & 296 & 0.133 & 0.06 \\
\hline
\end{tabular}

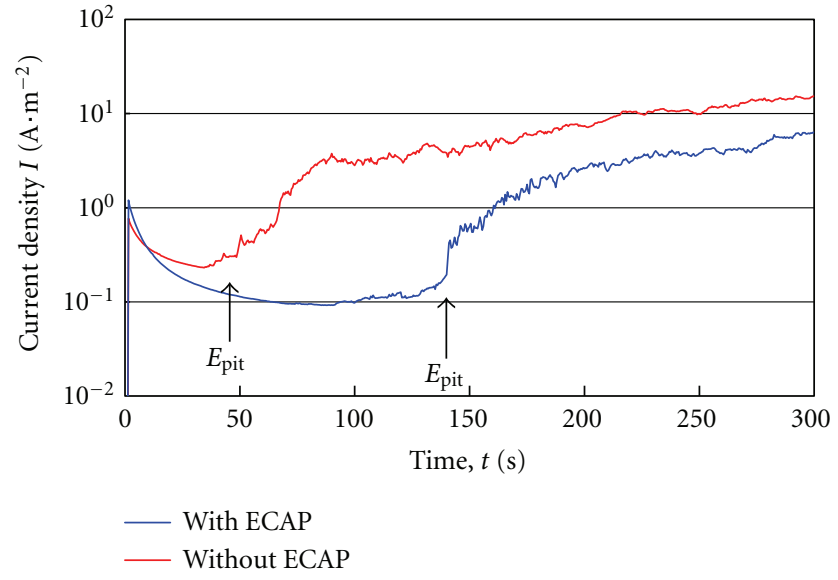

Figure 7: Time dependence of anodic current density of Al-Mg alloy with and without ECAP while kept at constant potential of $-0.2 \mathrm{~V}$ in a solution containing $0.1 \mathrm{~mol} \cdot \mathrm{L}^{-1}$ of $\mathrm{Na}_{2} \mathrm{SO}_{4}$ and $300 \mathrm{ppm} \mathrm{Cl}^{-}$.

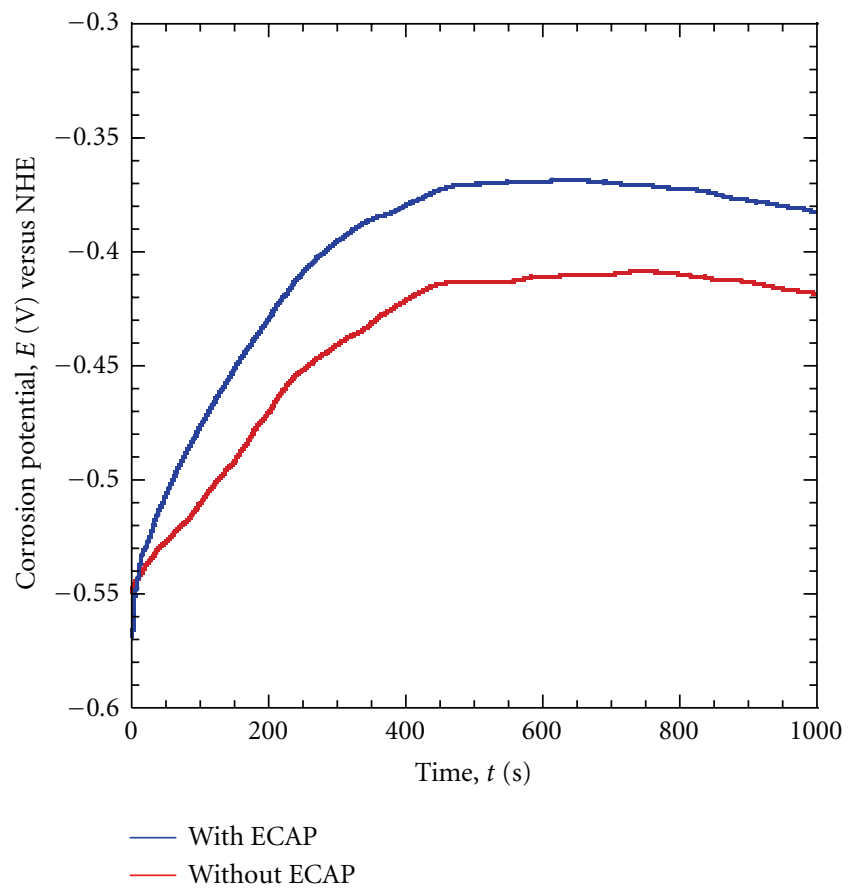

Figure 8: Time dependence of corrosion potential of AA5052 Al-Mg alloy with and without ECAP in a solution containing $0.1 \mathrm{~mol} \cdot \mathrm{L}^{-1}$ of $\mathrm{Na}_{2} \mathrm{SO}_{4}$ and $300 \mathrm{ppm} \mathrm{Cl}{ }^{-}$at $298 \mathrm{~K}$.

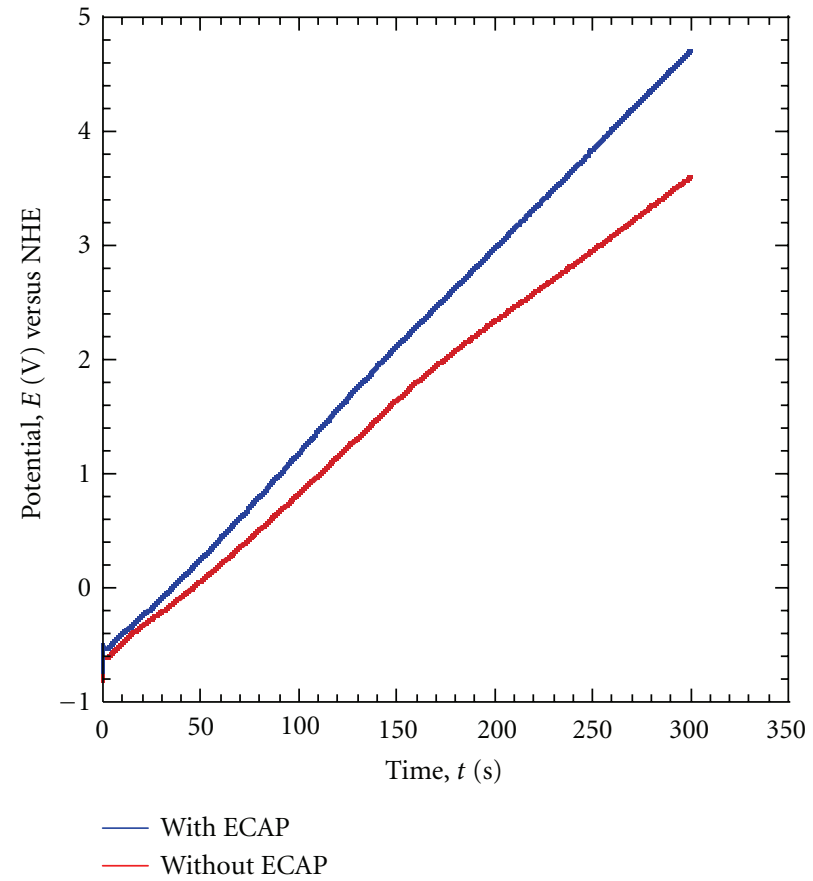

Figure 9: Time dependence of anodic potential of AA5052 Al-Mg alloy with and without ECAP at $1 \mathrm{~A} \cdot \mathrm{m}^{-2}$ in a solution containing $0.5 \mathrm{~mol} \cdot \mathrm{L}^{-1}$ of $\mathrm{H}_{3} \mathrm{BO}_{3}$ and $0.05 \mathrm{~mol} \cdot \mathrm{L}^{-1}$ of $\mathrm{Na}_{2} \mathrm{~B}_{4} \mathrm{O}_{7}$.

curve of the Al-Mg alloy. The anodic current densities rapidly increased at certain potentials when the anode potentials were shifted from $-0.8 \mathrm{~V}$ in the noble direction. This rapid increase in current density is caused by the initiation of pitting corrosion. The pitting corrosion potentials, at which pitting corrosion is initiated, were evidently shifted in the noble direction by ECAP, indicating improvement in the pitting corrosion resistance by application of ECAP. At a potential region more noble than the pitting corrosion potentials, the anodic current density was smaller with ECAP than without it, demonstrating that the corrosion resistance of the Al-Mg alloy was better with ECAP than without it.

Figure 7 shows the time dependence of the anodic current density of the Al-Mg alloy, while a constant potential of $-0.2 \mathrm{~V}$ was maintained around the pitting corrosion potential. The anodic current densities of the Al-Mg alloy increased sharply after certain periods of time owing to the initiation of pitting corrosion. The time required before initiating the pitting corrosion of the $\mathrm{Al}-\mathrm{Mg}$ alloy was longer with ECAP than without it. The anodic current density after pitting corrosion, or the growth rate of pitting corrosion, 


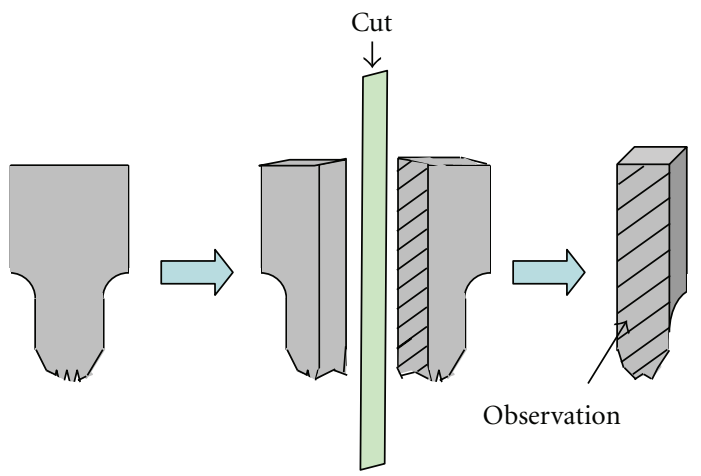

FIgure 10: Observation area shown in Figures 11 and 12 by SEM and EBSP.

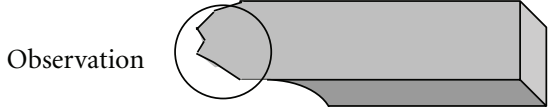

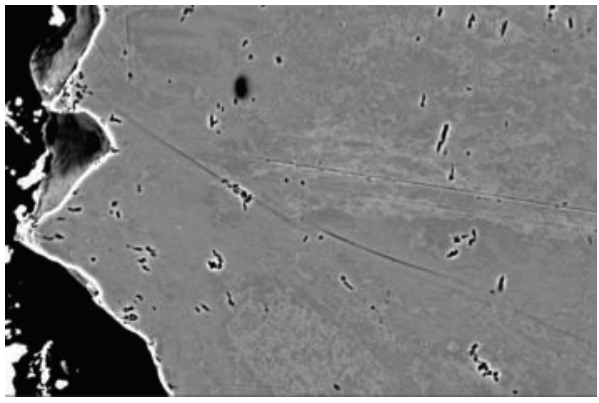

(a)

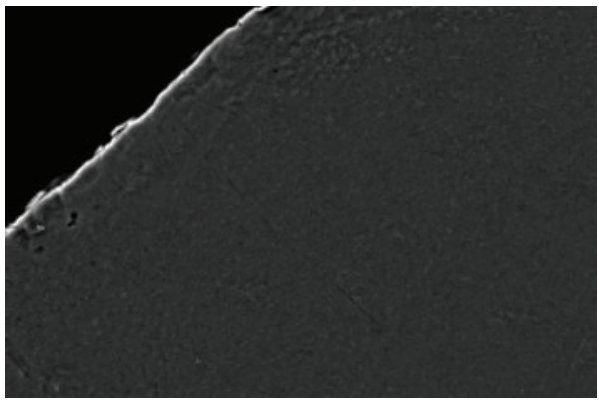

(c)

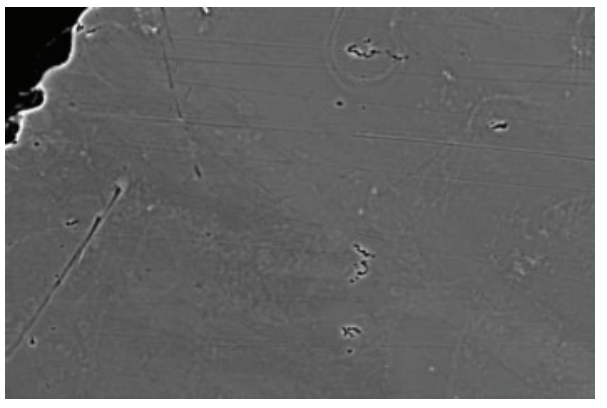

(b)

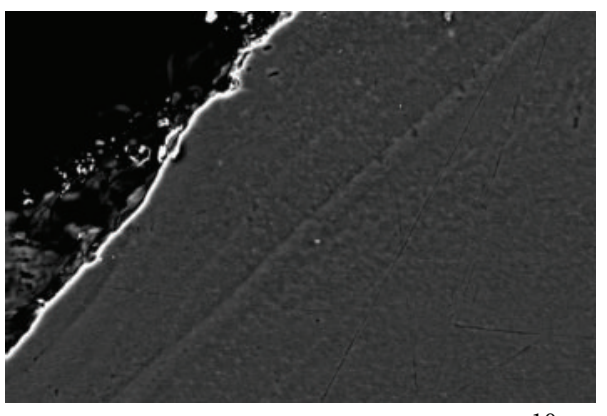

(d)

$10 \mu \mathrm{m}$

FIGURE 11: Angle-selective backscattered electron images of fracture area of Al-Mg alloy with and without ECAP after slow strain-rate tensile test. (a) Without ECAP, air (b) without ECAP, $\mathrm{NaCl}$ sol (c) with ECAP, air (d) with ECAP, $\mathrm{NaCl}$ sol.

was smaller with ECAP than without it. Further, the anodic current density before pitting corrosion was also smaller with ECAP than without it, demonstrating that the corrosion resistance of the Al-Mg alloy was better with ECAP than without it.

It has been reported that the corrosion potential of the AA5052 Al-Mg alloy in a solution containing $0.1 \mathrm{~mol} / \mathrm{L}$ of $\mathrm{Na}_{2} \mathrm{SO}_{4}$ and $300 \mathrm{ppm}$ of $\mathrm{Cl}^{-}$at $298 \mathrm{~K}$ shifted in the noble direction faster with ECAP than without it (Figure 8)
$[12,13]$. Further, the time dependence of anode potentials of the AA5052 Al-Mg alloy at $1 \mathrm{~A} / \mathrm{m}^{2}$ in a solution containing $0.5 \mathrm{~mol} / \mathrm{L}$ of $\mathrm{H}_{3} \mathrm{BO}_{3}$ and $0.05 \mathrm{~mol} / \mathrm{L}$ of $\mathrm{Na}_{2} \mathrm{~B}_{4} \mathrm{O}_{7}$ to form the barrier type of $\mathrm{Al}$ oxide film has been reported to show a faster shift of anode potential in the noble direction with ECAP (Figure 9) [12, 13]. Figures 8 and 9 suggest that the rate of formation of $\mathrm{Al}$ oxide films increases with ECAP. Since the $\mathrm{Mg}$ content of $\mathrm{Al}-\mathrm{Mg}$ alloy used in this study is relatively close to AA5052, Al-Mg alloy in this study seems to show 


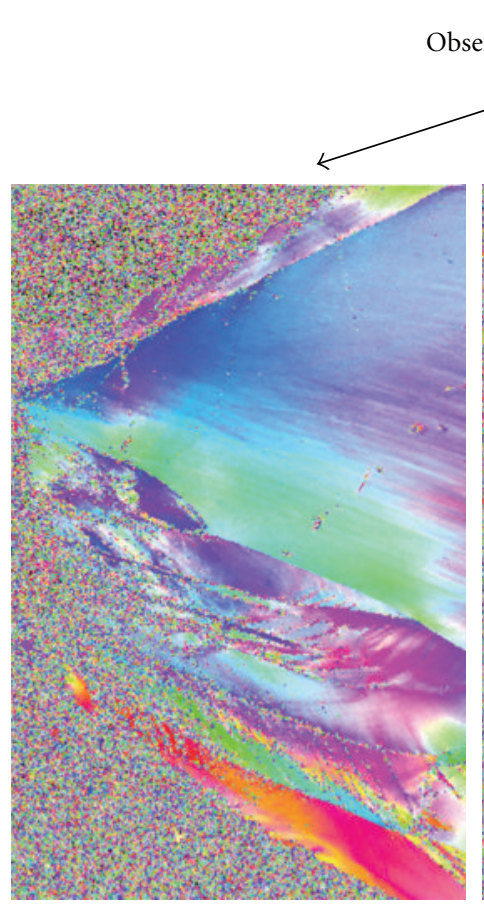

(a)

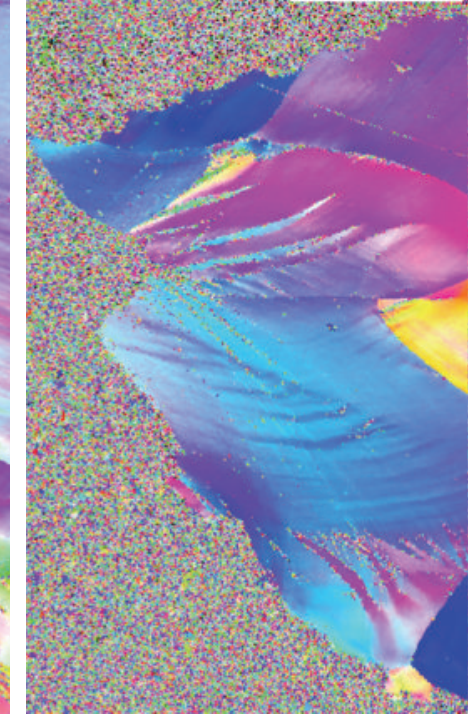

(b)

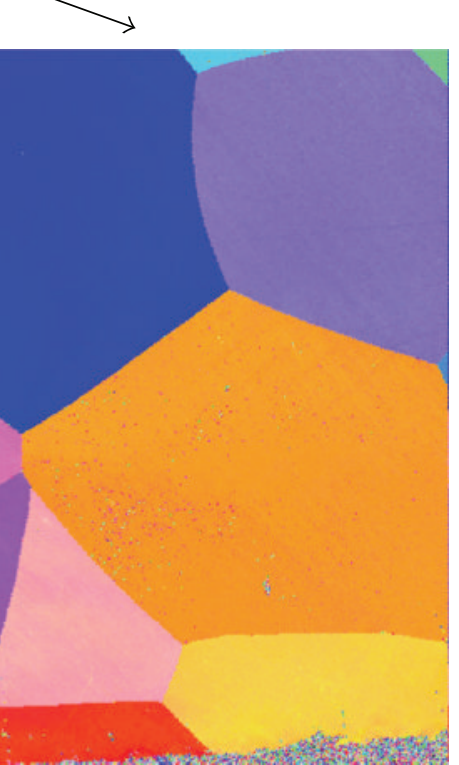

(c)

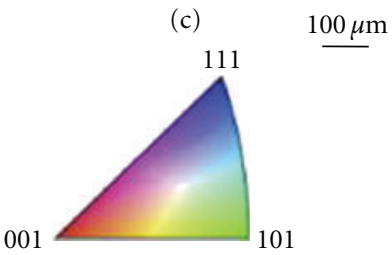

FIGURE 12: Crystal orientation mapping images of fracture area of Al-Mg alloy without ECAP after slow strain-rate tensile test. (a), (c) air (b) $\mathrm{NaCl}$ sol.

identical trend concerning the formation of $\mathrm{Al}$ oxide films with AA5052. It is well known that the oxidation reaction of metal occurs more quickly at crystalline lattice defects, such as grain boundaries and dislocations $[1,2]$. The ECAP process markedly increases the number of grain boundaries and the dislocation density in $\mathrm{Al}$. The oxidation rate of $\mathrm{Al}$ appears to increase as a result of the increase in the grain boundary and dislocation density caused by ECAP. It has been reported from electron microscope observations that multiple pitting corrosion occurred at the initial stage, but only pits that grow readily at the initial stage ultimately develop into macropits, since most pits are unstable and are immediately repassivated [2]. The specimen that quickly forms oxide films seems to be immediately repassivated, resulting in no growth of pitting corrosion, even when pitting corrosion occurs at the initial stage. In this study, the improvement of corrosion resistance with ECAP can be ascribed to the increase in the oxidation rate due to the decreased grain size of Al. The decrease in $I\left(\sigma_{\max }\right)$ and $I(\delta)$ of the $\mathrm{Al}-\mathrm{Mg}$ alloy with ECAP can be attributed to improvement of corrosion resistance with ECAP.

3.2. Observation of Fracture Area after Slow Strain-Rate Tensile Test. The specimen was cut at the center, as shown in
Figure 10, and was embedded in a conductive resin followed by mirror polishing and Ar sputtering to investigate the internal texture after tensile test. Figure 11 shows angleselective backscattered electron images of the fracture area of the Al-Mg alloy with and without ECAP after a slow strainrate tensile test in a $3 \% \mathrm{NaCl}$ solution. Many voids were present in the vicinity of the fracture area without ECAP (Figures 11(a) and 11(b)), suggesting a void connection-type fracture. The number of voids was larger after the tensile test in air than in $\mathrm{NaCl}$ solution. Since elongation is higher in air, the voids seem to form with increasing strain. The Al$\mathrm{Mg}$ alloy with ECAP showed a straight fracture at an angle of inclination of approximately $45^{\circ}$ and rarely showed necking (Figures 11(c), 11(d)). In the Al-Mg alloy with ECAP, there was little difference in morphology between air and $\mathrm{NaCl}$ solution, and voids were rarely observed without ECAP.

Figure 12 shows crystal orientation mapping images of the fracture area of the Al-Mg alloy without ECAP after a slow strain-rate tensile test in air and $\mathrm{NaCl}$ solution. The tip of the fracture area showed a nonuniform crystal plane due to the introduction of a dislocation with deformation after a tensile test in air and $\mathrm{NaCl}$ solution (Figures 12(a) and 12(b)). The crystal grain deformed in air, while in the $\mathrm{NaCl}$ solution, the deformation was small and the fracture seemed 
to originate from the grain boundary. In the Al-Mg alloy with ECAP, the crystal grain cannot be identified by EBSP because of the small grain size.

\section{Conclusion}

Stress-corrosion cracking property of the Al-Mg alloy processed by equal-channel angular pressing was investigated by a slow strain-rate tensile test in the $\mathrm{NaCl}$ solution. The susceptibility of stress-corrosion cracking was evaluated by $I\left(\sigma_{\max }\right)$ and $I(\delta)$, which express the decrease ratio of maximum stress and total elongation in the $\mathrm{NaCl}$ solution to those in air. $I\left(\sigma_{\max }\right)$ and $I(\delta)$ decreased with ECAP, showing that the susceptibility of stress-corrosion cracking was smaller with ECAP than without it. The polarization curves and the anodic current density of the Al-Mg alloy at constant potential in the $\mathrm{NaCl}$ solution revealed a decrease in the anodic current density with ECAP, or an improvement in corrosion resistance with ECAP. The decrease in $I\left(\sigma_{\max }\right)$ and $I(\delta)$ of the Al-Mg alloy with ECAP shows that corrosion resistance is improved by ECAP.

\section{Acknowledgment}

This study was supported by the Grant-in-Aid for Scientific Research on Innovation Areas (research in a proposed research area no. 23102505) of the Ministry of Education, Culture, Sports, Science \& Technology of Japan in 2011.

\section{References}

[1] H. H. Uhlig, Corrosion and Corrosion Control, Sangyo Tosho, Tokyo, Japan, 1968.

[2] G. Ito, Corrosion Science and Engineering, Corona, Tokyo, Japan, 1973.

[3] S. Osaki, H. Kondo, and K. Kinoshita, "Effect of Cr addition on SCC property of Al-Mg-Si alloys," Journal of Japan Institute of Light Metals, vol. 55, no. 8, pp. 350-356, 2005.

[4] S. Osaki, S. Horie, K. Kinoshita, S. Sato, M. Adachi, and T. Maeda, "Mechanical and SCC properties of rheocast 7075 based aluminum alloys," Journal of Japan Institute of Light Metals, vol. 55, no. 1, pp. 27-32, 2005.

[5] H. Adachi, K. Osamura, and J. Kusui, "Relationship between stress corrosion resistance and microstructure of rapidly solidified Al-Zn-Mg alloys," Journal of Japan Institute of Light Metals, vol. 54, no. 2, pp. 69-74, 2004.

[6] R. Z. Valiev, N. A. Krasilnikov, and N. K. Tsenev, "Plastic deformation of alloys with submicron-grained structure," Materials Science and Engineering A, vol. 137, pp. 35-40, 1991.

[7] R. Z. Valiev, R. K. Islamgaliev, and I. V. Alexandrov, "Bulk nanostructured materials from severe plastic deformation," Progress in Materials Science, vol. 45, no. 2, pp. 103-189, 2000.

[8] Y. T. Zhu, T. G. Langdon, R. S. Mishra, S. L. Semiatin, M. J. Saran, and T. C. Lowe, Ultrafine Grained Materials. II, The Minerals, Metals \& Materials Society, Warrendale, Pa, USA, 2002.

[9] Z. Horita, M. Furukawa, M. Nemoto, and T. G. Langdon, "Development of fine grained structures using severe plastic deformation," Materials Science and Technology, vol. 16, no. 11-12, pp. 1239-1245, 2000.
[10] Z. Horita, "Production of ultrafine-grained structures using equal-channel angular pressing," Journal of the Japan Welding Society, vol. 74, no. 2, pp. 88-91, 2005.

[11] K. Ohishi, K. Kaneko, and Z. Horita, Materia Japan, vol. 41, no. 6, pp. 422-426, 2002.

[12] I. J. Son, H. Nakano, S. Oue, S. Kobayashi, H. Fukushima, and Z. Horita, "Pitting Corrosion Resistance of Ultrafine-Grained Aluminum Processed by Severe Plastic Deformation," Journal of the Japan Institute of Metals, vol. 69, no. 10, pp. 892-898, 2005.

[13] I. J. Son, H. Nakano, S. Oue, S. Kobayashi, H. Fukushima, and Z. Horita, "Pitting corrosion resistance of ultrafine-grained aluminum processed by severe plastic deformation," Materials Transactions, vol. 47, no. 4, pp. 1163-1169, 2006.

[14] I. J. Son, H. Nakano, S. Oue, S. Kobayashi, H. Fukushima, and Z. Horita, "Pitting corrosion resistance of anodized aluminum alloy processed by severe plastic deformation," Journal of the Japan Institute of Metals, vol. 70, no. 7, pp. 534-540, 2006.

[15] I. J. Son, H. Nakano, S. Oue, S. Kobayashi, H. Fukushima, and Z. Horita, "Pitting corrosion resistance of anodized aluminum alloy processed by severe plastic deformation," Materials Transactions, vol. 48, no. 1, pp. 21-28, 2007. 

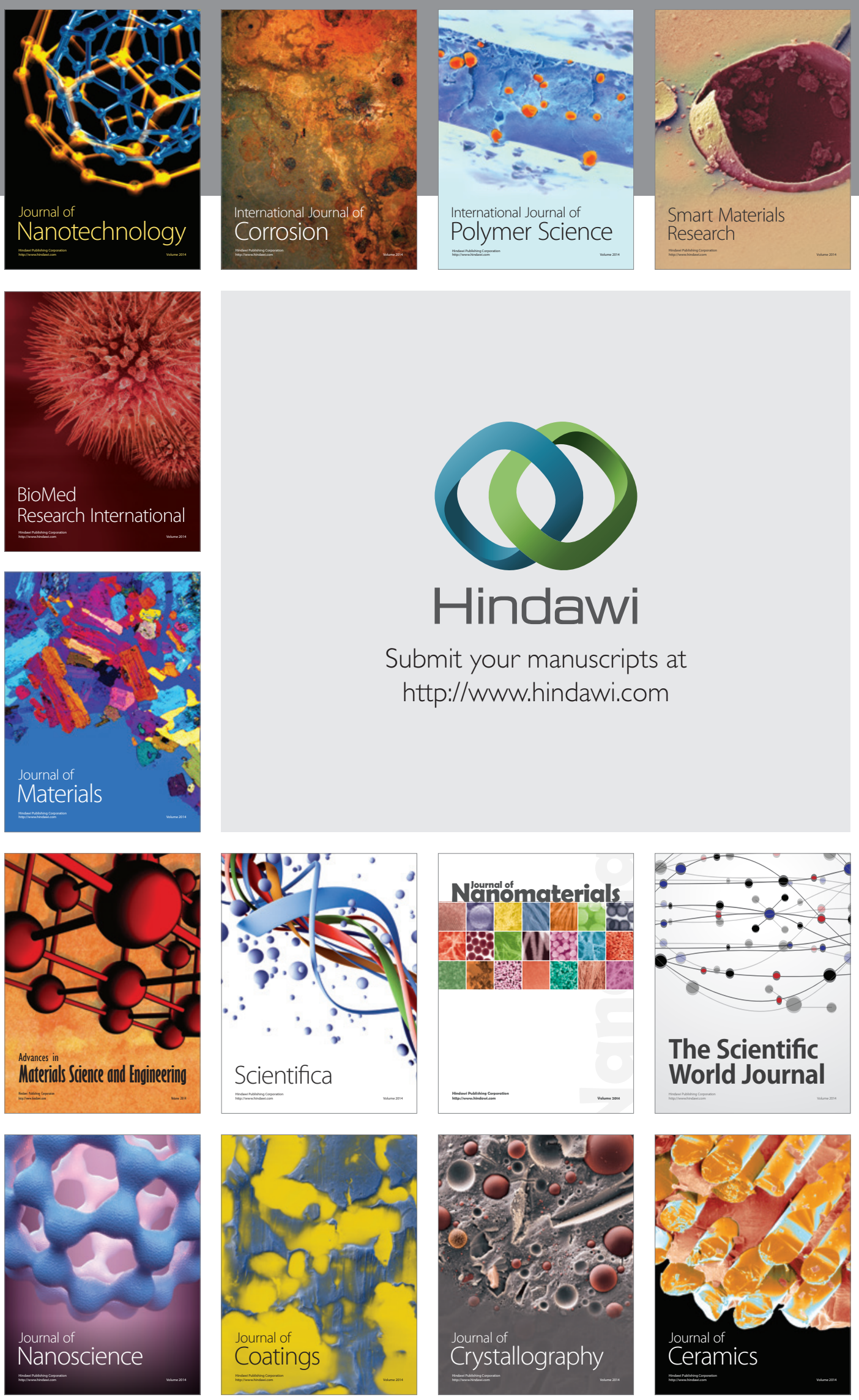

The Scientific World Journal

Submit your manuscripts at

http://www.hindawi.com

\section{World Journal}

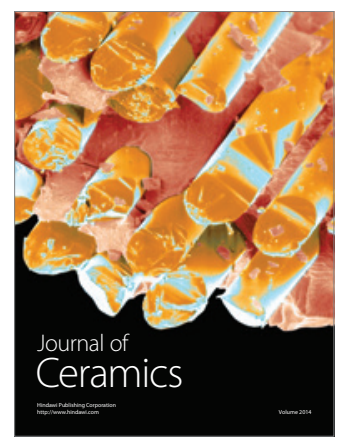

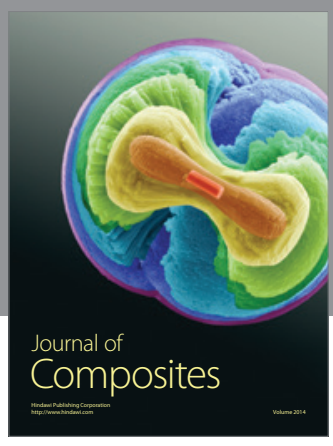
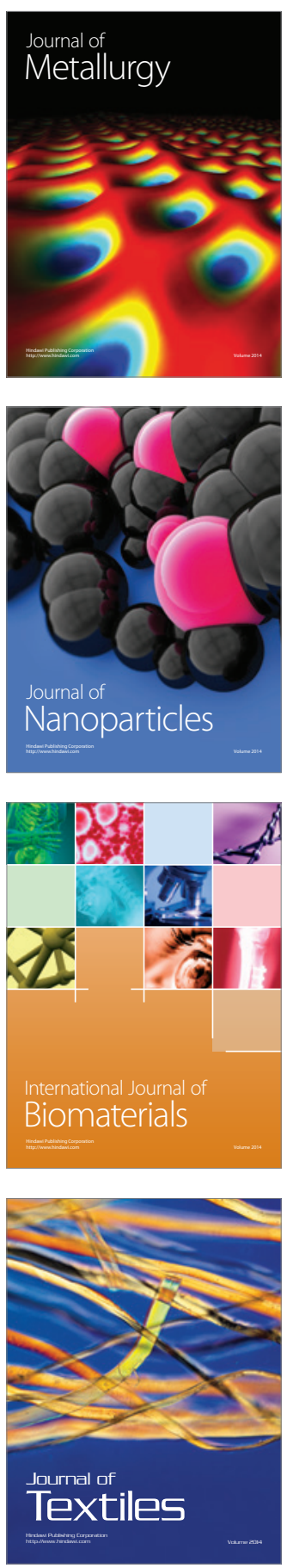